УДК 377.031

DOI: 10.23951/1609-624X-2020-1-24-32

\title{
ОБРАЗОВАТЕЛЬНЫЙ ПОТЕНЦИАЛ РЕГИОНАЛЬНОЙ СРЕДЫ В СИСТЕМЕ РАЗВИТИЯ ПОЛИЭТНИЧЕСКОЙ КУЛЬТУРЫ ШКОЛЬНИКОВ
}

\author{
Г. И. Егорова ${ }^{1}$ Н. М. Сязи ${ }^{2}$ Б. М. Чабарова ${ }^{3}$
}

${ }^{1}$ Тюменский индустриальный университет, Тюмень

${ }^{2}$ Муниципальное бюджетное образовательное учреждение 2, Тарко-Сале

${ }^{3}$ Тюменский государственный университет, Тюмень

\begin{abstract}
Введение. Обращение педагогов, ученых к научному концепту «региональная среда» - своевременная необходимость в связи с глобальными изменениями и углублением культурных различий каждого региона. Знание достижений многонациональной среды региона рассматривается как важное условие развития полиэтнической культуры, обеспечивающей бесконфликтное взаимодействие школьников с представителями разных культур и важный фактор осознанного понимания регионального конструкта «прошлое, настоящее, будущее» региона в единстве и во взаимосвязи.

Цель - раскрыть возможности учебных средств на основе многонациональной среды региона в развитии полиэтнической культуры школьников, выявить их функционально-дидактическое значение, условия применения.

Материалы и методы. Материалом для исследования стали разработанные учебные средства на основе многонациональной среды региона: содержательные модули, средства на печатной основе (таблицы, карты, развивающие задания, технологии). Применялись следующие методы: теоретико-методологический анализ ведущих концепций по исследуемой теме, проведение контент-анализа, выборка ведущих авторов по исследуемой проблеме, сравнительный, сопоставительный анализ. В ходе изучения педагогического опыта использовался метод классификации, аналогий, контент-анализ. Эмпирические методы включали анкетирование, беседу, сравнительный анализ. Статистические методы были основаны на методах математического анализа.

Результаты и обсуждение. Разработаны и внедрены содержательные модули на основе многонациональной среды региона, усиливающие вариатив и инвариант предметного знания: культурологический модуль раскрывает полиэтническую функцию предметного знания через изучение культуры этносов, их роли в развитии региона; исторический модуль создает целостное представление об истории региона, многонациональных стройках, героях, первооткрывателях земли сибирской; эколого-географический модуль учитывает условия проживания этносов при быстрой смене технологий; социально-экономический модуль показывает роль этносов в освоении природных ресурсов, промышленности региона. Доказана необходимость поэтапного развития полиэтнической культуры школьников через последовательное включение учебных средств на основе многонациональной среды региона: тексты, таблицы, карты (именные, когнитивные, информационные), веб-квесты; система развивающих заданий, интерактивных технологий, актуализирующих знания и умения полиэтнического характера.

Заключение. В завершении подводится итог выполненного исследования, раскрывается практическая значимость использования учебных средств на основе многонациональной среды региона как основы развития полиэтнической культуры школьников.
\end{abstract}

Ключевые слова: регион, региональное пространство, региональная среда, средства обучения, полиэтническая культура.

\section{Введение}

Педагогическое осмысление понятий «регион», «региональное пространство», «региональная среда» закономерно входит в образовательную теорию и практику. Само понятие «регион» является концептуально обоснованным и разработанным. Авторские точки зрения ученых в большей степени ориентированы на понимании регионов «как мобильных, динамичных пространств» [1, с. 7]. Научный концепт «регион» разработан Э. Дюркгеймом, указавшим на интеграцию и дифференциацию как законов развития регионального пространства. Однако с развитием цивилизации происходит усложнение и преобразование регионов. В рамках современных инновационных преобразо- ваний происходит, с одной стороны, унификация культур, с другой - наблюдается углубление культурных различий. Нельзя не согласиться с мнением о том, что учащиеся ближнего и дальнего зарубежья - это носители другой культуры, языка, а самое трудное препятствие для них - это различие в культурных основах обучения [2, с. 11].

Научное понимание современного региона связано с уходом его от онтологических параметров к программе социального конструктивизма, что доказывает его новый статус социального конструкта. В этих измерениях главная задача педагогического сообщества - создать в сознании субъектов образовательного процесса элементы «сборки» региона в культурном, историческом, научном, эко- 
номическом развитии. Параметры конструирования современного региона в любом измерении возможны с учетом специальных средств развития полиэтнической культуры на основе многонациональной среды.

Каждый регион имеет свою географическую структуру. Данная точка зрения не требует особых доказательств, так как сложилась исторически. Культурно-историческая обусловленность региона определяет его как территориально-компактное сообщество с определенной экономической, политической, культурной, пространственной структурой, что отличает его от других сообществ. Педагогический аспект современного понимания региона важен для осмысления с нескольких позиций. Вопервых, это выбор и обоснование учебных средств развития полиэтнической культуры. Во-вторых, с позиции экзистенциального аспекта регион рассматривается как возможность дальнейшего проживания и существования школьника - субъекта образовательной деятельности. Важность этого аспекта очевидна, так как многонациональный регион - это люди разных национальностей, которые ищут ресурсы для самореализации и позиционирования. Значимость региональных связей (природные ресурсы, культурные ценности, экономические, социально-исторические, эколого-географические связи) важна для субъектов в плане развития общих интересов. Такая уникальность значений связана прежде всего с повседневным опытом людей, проживающих в регионе. В социокультурном измерении мы рассматриваем регион как систему культурных практик, совокупность связей, особое жизненное пространство будущего и настоящего школьника. Активное заселение северных территорий России привело к значительным сдвигам в этническом составе населения, что выдвигает много педагогических проблем: сохранение уникальной культуры народов региона, развитие полиэтнического взаимодействия и коммуникаций.

Для Тюменского региона как современного нефтегазохимического кластера характерны интеграционные процессы, повышение уровня социокультурного, научного обмена, сотрудничества, что обеспечивает инновационное преобразование статуса региона. Однако при этом обособление северных народов и культур становится невозможным. В общеобразовательных школах увеличивается число этнически смешанных семейных пар, что требует значительного расширения этнического и полиэтнического общения. Кроме того, стремительный рост населения региона за счет мигрантов приводит к замене моноэтнической ситуации в школе на полиэтническую. Данная ситуация в школьной образовательной среде, с одной стороны, требует сохранения этничности школьника, а с другой стороны, возникает необходимость образования школьника в иной культурной среде. Отметим, что многонациональная среда Тюменского региона сегодня приобретает новый статус: от нефтегазодобывающего, перерабатывающего региона до духовного, культурного центра России. Современное измерение многонациональной среды Тюменского региона определяется как целостное системное явление, которое требуется учитывать при развитии полиэтнической культуры [3]

Нельзя не отметить, что развитие региона связано с появлением особой сибирской идентичности населения, которая складывалась исторически с учетом влияния культур востока, запада, севера и юга российского государства, которые объединяют в историческом ракурсе многие этносы (ханты, манси, ненцы, татары и другие) [4]. Тюменский регион как единая социальная общность ориентирован на сохранение идентичности каждого человека.

Однако, как показывает опрос учителей, школьников, в регионе идет снижение интереса к региональным культурным и духовным ценностям. При этом, с одной стороны, происходит размывание культуры коренных жителей, отсутствие системы преемственности традиций многонационального региона, с другой стороны, наблюдается изменение статуса Тюменского региона, который требуется учитывать в образовательном процессе. Многие столетия на территории региона складывалась особая социокультурная среда, которая позволяла осознать многонациональные процессы через содержательный компонент развития полиэтнической культуры.

\section{Материалы и методы}

Методологическую основу исследования составляют ведущие положения и идеи: деятельностного подхода как основы успешной организации деятельности субъектов по использованию средств многонациональной среды региона с опорой на возрастание доли самостоятельной, исследовательской деятельности по поиску, освоению, закреплению полиэтнической информации; регионального подхода, раскрывающего полиэтническую реальность в сознании субъектов как совокупности знаний (научных, культурных, технических), формирующих региональную картину в ее материальной, духовной составляющих; культурологического подхода, обосновывающего полиэтническую культуру как: а) часть культуры школьника; б) особую ценность с учетом освоения этнической культуры как платформы развития полиэтнической культуры.

Материалом для исследования стали разработанные учебные средства на основе многонациональной среды региона: содержательные модули, 
средства на печатной основе (таблицы, карты, развивающие задания, технологии).

\section{Результаты и обсуждение}

В научной литературе бытует мнение, что региональное пространство само по себе является результатом взаимодействия следующих видов пространств, таких как социально-экономическое, историческое, культурное, информационное. При этом все эти виды пространств как бы полностью включены в жизненное пространство школьника, которое выстраивается из определенных человеческих, многонациональных жизненных историй, имеет свой менталитет, мировоззрение, традиции.

В исследовании А. М. Демина обосновывается главенствующая точка зрения - наличие региональной среды, к которой автор относит природу, историю, культуру, язык. Данные компоненты региональной среды представлены в базисном учебном плане такими образовательными областями, как естествознание, обществознание, филология, искусство. При этом история, культура понимаются в широком плане: история цивилизации и своего этноса; мировая культура с элементами культуры своего этноса; язык основа коммуникации в глобальном, региональном масштабах; природа, ландшафт, флора и фауна, экологические проблемы все указывает на взаимосвязь и целостность современной региональной среды [5].

В региональном измерении Н. Ю. Буряк приоритет отдает взаимодействию пространств культур как интегральной среды (ценности, нормы), которая занимает «сверхпозицию» на основе коммуникации пространств культуры. Это интегральная культурная среда позволяет увидеть «транзит настоящего в прошлое» в единстве и во взаимосвязи [6]. В педагогическом аспекте можно говорить не только о структурной неоднородности как свойстве региональной среды, но и о ее иерархичности. Из этого вытекает еще одно свойство региональной среды - ее «фрактальность», когда одна среда, являясь самостоятельным образованием, как бы «вложена» в другую. Географическая среда включает количественные, качественные характеристики территории, природы, ресурсов, границ. Экологическая среда связана с сохранением флоры, фауны, национальных природных богатств региона. Историческая среда обоснована включением исторического наследия, наличием национальных героев, фактов, что развивает историческую память школьника. Социальная среда включает деятельность индивидуумов, социальных групп, образовательных систем. Экономическая среда создает совокупность поликультурных, национальных достижений как в промышленности, так и в экономике. Культурная среда включает субъекта в культурное наследие, знакомит с ценностями, культурой современности, культурой разных народов, мифологией. Информационная среда - включение информационных технологий, телекоммуникация, СМИ, построение виртуального взаимодействия.

Главной детерминантой, с педагогической точки зрения, является конструирование региона в сознании школьника как многонациональной среды в eе институционально-политическом, экономическом, культурном, историческом, информационном, экологическом измерениях. Эти положения обосновывают возможность дополнения содержания принципа региональности как стратегического руководства педагогическому сообществу по созданию многонационального регионального конструкта в сознании школьника с учетом усвоения информации о культуре, науке, традициях, ценностях народов региона через совместную культуросозидательную, творческую работу субъектов образовательной деятельности, имеющих свою этническую культуру.

Таким образом, территория, где проживает школьник, побуждает его к познанию, оценке регионального мира, совершать конкретные практические дела, осваивать и принимать традиции, достижения, культурные отличия различных этнических общностей.

Создание такого конструкта обеспечивает развитие полиэтнической культуры школьников через совместную культуросозидательную, творческую работу педагога и школьника как субъекта, имеющего свою индивидуально-этническую среду с опорой на изучение, осознание знаний многонациональной среды региона. Исходной позицией для нас является этническая среда субъекта - как формы личного опыта взаимодействия субъекта с культурой своего этноса. Оперирование этническими понятиями создает некоторое начало полиэтнического взаимодействия, полиэтнической активности субъекта (рис. 1).

Выделим некоторые специфические черты Тюменского региона: а) уникальность географического положения территории по размерам; б) уникальность геостратегического положения с севера на юг (от берегов Карского моря до Казахстана); в) включение трех субрегионов (юг области; Ханты-Мансийский автономный округ; Ямало-Ненецкий автономный округ) обеспечивает различия в геополитических интересах юг-север; г) высокий ресурсный потенциал (месторождения нефти, газа и газового конденсата), его переработка обеспечивают экономический рост главного региона России; д) самый многонациональный регион России, Центрального Евро-Азиатского континента, имеющий особую этнодемографическую историю, развитые миграционные процессы; ж) уникальность 
культурного, исторического, научного развития региона: многонациональные экспедиции (П. С. Паллас, И. П. Фальк); ссыльные писатели (А. Грин, Ф. М. Достоевский, В. А. Жуковский, В. Г. Короленко, А. Н. Радищев, К. М. Станюкович, Н. Г. Чернышевский, А. П. Чехов); традиционное место ссылки передовых людей России (декабристы и их роль в развитии многонациональной культуры, образования); города Сибири - традиционные многонациональные центры жизни, образования и культуры (Тобольск, Салехард, Сургут, Тюмень); водные, сухопутные пути (царская, бабиновская дороги); многонациональный состав ученых (химик Д. И. Менделеев, картограф С. У. Ремезов, изобретатель телевидения Б. П. Грабовский; иностранные ученые-натуралисты (А. Э. Брем, А. Гумбольдт, Д. Г. Мессершмидт, Г. Ф. Миллер, Ф. Нансен и др.), принимающие участие в развитии региона, культуры многочисленных народов.

Обзор, теоретическое и практическое осмысление структуры Тюменского края показали, что многонациональная среда региона является, с одной стороны, интегратором, а с другой - генератором поликультурного взаимодействия на основе традиций и инноваций, объединяющих в регионе людей.

При этом подчеркнем важность создания системы непрерывного полиэтнического просвещения, чтобы ориентировать школьников как будущих жителей региона в выстраивании персонального полиэтнического взгляда.

Идее развития полиэтнической культуры через преобразование компонентов содержания не уделялось достаточного внимания. С позиции Д. С. Лихачева отметим, что структура содержания и его объем задаются обществом, стандартами [7].

Принимая во внимание современные требования к конструированию содержания, а также исследования по проблеме развивающего и поликультурного образования, рассматриваем содержательные модули как элемент системы развития полиэтнической культуры, как средство развития полиэтнической культуры с учетом способов ранжирования материала на основе выделения рангов, которые выстраивают материал от неглубокой сущности к более глубокой сущности.

Основные принципы выбора содержания: научность, доступность, систематичность, которые усиливают полиэтническое содержание в вариативной, инвариантной части гуманитарного и естественно-научного предметного содержания по следующим направлениям.

Включение культурологического модуля повышает интерес учащихся к полиэтническим фактам, что усиливает полиэтническую функцию предметного знания; введение исторического модуля со- здает целостное представление о взаимосвязанном развитии предметного знания, истории, роли края и величайших представителей региона в истории человечества; использование эколого-географического модуля развивает умение оценивать влияние многонациональной среды региона на экологическое, географическое состояние; введение сочиально-экономического модуля ориентирует на приведение в систему знаний о родном крае, создание целостной картины региона, включение ее в общую картину многонационального мира (таблица). Содержательные модули развития полиэтнической культуры выбраны с учетом принципов взаимосвязи глобального, общенационального, регионального (К. Ш. Ахиярова, А. Н. Джуринский, Ю. В. Смирнова [8-10]); единства когнитивного, ценностного компонентов в деятельности школьников (Л. П. Карпушина [11]).

Следует отметить, что выделенные модули это банк данных для педагога по различным проблемам истории, техники и культуры региона, создания интегрированных курсов в области краеведения. В рамках развития полиэтнической культуры используются основные виды деятельности учителя-краеведа: сбор, обработка документальных и исторических первоисточников, участие в экскурсионно-экспедиционной работе, проектная деятельность для познания своего края, как отмечает И. С. Матрусов [12].

В современных условиях диверсификации региональной политики, перехода в новые социально-экономические отношения уже недостаточно использовать только краеведение, которое мы рассматриваем не только как элемент школьного образования.

Необходимо выделять новые формы, средства обучения: языки, региональная наука, литература, новые региональные, этнические взаимоотношения, особенно в условиях миграции различных культур. Само понятие «краеведение» имеет некоторые устоявшиеся границы в педагогическом образовании: изучение родного края; культурное пространство; средство формирования гражданской позиции; лаборатория для исследователей. Получил распространение региональный подход как педагогический принцип, общая стратегия решения образовательных задач с включением общего и особенного регионального содержания.

Для выявления возможностей предметных областей в развитии полиэтнической культуры школьников проведен анализ используемых программ, учебников в общеобразовательных школах Тюменского региона. В разных программах вопрос развития полиэтнической культуры школьников при обучении присутствует в большей или меньшей степени, по-разному представлен по годам обучения. 


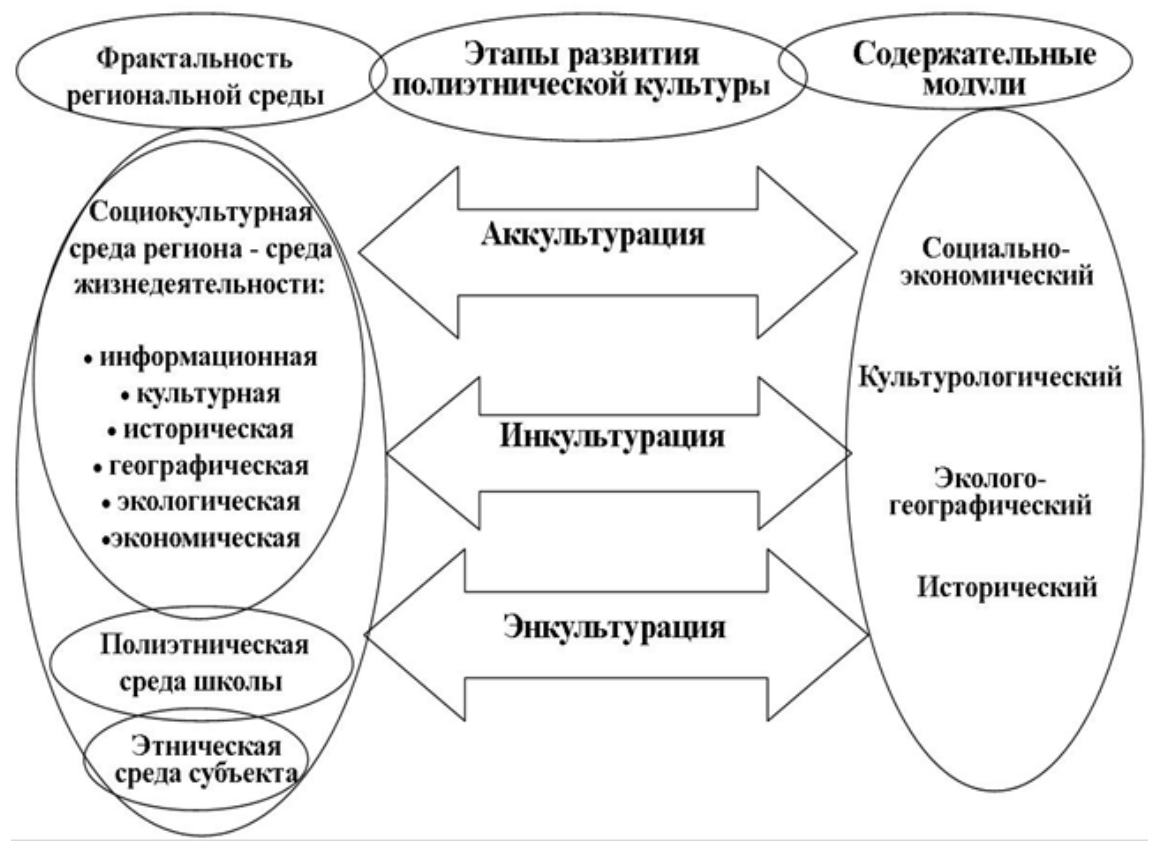

Рис. 1. Содержательные модули в параметрах фрактальности региона

Функиионально-дидактическое значение учебных средств на основе многонациональной среды региона

\begin{tabular}{|c|c|c|c|}
\hline $\begin{array}{c}\text { Средства многонациональной } \\
\text { среды региона }\end{array}$ & $\begin{array}{c}\text { Педагогические приемы } \\
\text { использования средств }\end{array}$ & $\begin{array}{c}\text { Элементы деятельности } \\
\text { школьника }\end{array}$ & $\begin{array}{l}\text { Функциональное } \\
\text { значение средств }\end{array}$ \\
\hline \multicolumn{4}{|c|}{ 1-й этап - энкультурация - развитие этничности } \\
\hline Тексты & \multirow{4}{*}{$\begin{array}{l}\text { Работа с готовой полиэтниче- } \\
\text { ской информацией (формули- } \\
\text { ровка, пересказ, воспроизведе- } \\
\text { ние, выявление этнического } \\
\text { характера) }\end{array}$} & \multirow{4}{*}{$\begin{array}{l}\text { Знакомство с полиэтническим } \\
\text { миром, интерес к этнической } \\
\text { информации. } \\
\text { Осознание своей этнической } \\
\text { принадлежности. } \\
\text { Потребность в коммуникации }\end{array}$} & \multirow{4}{*}{$\begin{array}{l}\text { Средства дополнительной } \\
\text { полиэтнической инфор- } \\
\text { мации }\end{array}$} \\
\hline Таблицы & & & \\
\hline $\begin{array}{l}\text { Карты (именные, } \\
\text { информационные) }\end{array}$ & & & \\
\hline Содержательные модули & & & \\
\hline & \multicolumn{3}{|c|}{ 2-й этап - инкультурация - полиэтническая образованность } \\
\hline Презентации Power Point & \multirow{4}{*}{$\begin{array}{l}\text { Частично-поисковые задания, } \\
\text { решение проблемных ситуа- } \\
\text { ций на развитие гражданской } \\
\text { идентичности: патриотизма, } \\
\text { уважения к народу региона }\end{array}$} & \multirow{4}{*}{$\begin{array}{l}\text { Присвоение, анализ полиэтни- } \\
\text { ческой информации. } \\
\text { Межэтническое взаимопозна- } \\
\text { ние, взаимопроникновение, } \\
\text { доверие, взаимопонимание }\end{array}$} & \multirow{4}{*}{$\begin{array}{l}\text { Средства систематизации, } \\
\text { коммуникации, выхода за } \\
\text { границы заданной } \\
\text { полиэтнической инфор- } \\
\text { мации }\end{array}$} \\
\hline $\begin{array}{l}\text { Электронные поисковые } \\
\text { системы }\end{array}$ & & & \\
\hline Веб-квесты & & & \\
\hline $\begin{array}{l}\text { Интерактивные технологии } \\
\text { (диалог, работа в команде) }\end{array}$ & & & \\
\hline \multicolumn{4}{|c|}{ 3-й этап - аккультураччия - развитие полиэтничности } \\
\hline $\begin{array}{l}\text { Решение исследовательской } \\
\text { проблемы, задания }\end{array}$ & $\begin{array}{l}\text { Творческие, исследовательские } \\
\text { виды деятельности по } \\
\text { получению нового знания. } \\
\text { Решение социально-проектных } \\
\text { ситуаций, теорий. } \\
\text { Приемы на развитие } \\
\text { мировоззренческой позиции }\end{array}$ & $\begin{array}{l}\text { Межэтническая интеграция. } \\
\text { Взаимоотношения. Удовлетво- } \\
\text { ренность взаимодействием. } \\
\text { Совместная деятельность. } \\
\text { Самостоятельный поиск } \\
\text { полиэтнической информации }\end{array}$ & $\begin{array}{l}\text { Средства расширения } \\
\text { поля межэтнического } \\
\text { взаимодействия. } \\
\text { Усвоение, присвоение } \\
\text { полиэтнической } \\
\text { информации }\end{array}$ \\
\hline
\end{tabular}

Анализ программ и учебников обнаруживает, что в большей степени элементы развития полиэтнической культуры учащихся могут быть реализованы в дисциплинах естественно-научного и гуманитарного направления, авторских программах, элективных дисциплинах [13].

Анализ результатов анкетирования учителей гуманитарного, естественно-научного направления показал, что в каждой предметной области имеют- ся разделы, направленные на развитие полиэтнической культуры.

При этом следует более широко использовать не только традиции, культурные ценности народов, но и более широко освещать природные, технические, научные, экономические, экологические достижения с древнейших времен до наших дней. Анализ педагогической практики и личного опыта работы в общеобразовательной школе позволил 
определить круг проблем, требующих внимания для осуществления процесса развития полиэтнической культуры:

- отсутствие возможности варьировать учебными часами для включения модулей в предметы 5-11-х классов;

- слабое использование знаний гуманитарного и естественно-научного направления в развитии полиэтнической культуры;

- отсутствие сведений о полиэтническом взаимодействии, выдающихся людях в культуре народов Тюменского края;

- в общеобразовательных школах 5-15 \% часов вариативной части учебного плана использовано на факультативные курсы с учетом краеведческого материала;

- 7-10\% программ факультативов гуманитарного направления реализуют вопросы полиэтнического характера, в большей степени иностранные языки;

- программы предметов естественно-научного направления (2-4 \%) не включают материал полиэтнического содержания;

- учащимся предлагается ограниченный перечень факультативов, предметов по выбору, не учитывая этнические интересы учащихся.

Следует отметить возможность пропедевтической работы по развитию полиэтнической культуры школьников при обучении в начальной школе (1-3-й классы).

И. С. Матрусов в преподавании естественно-научных предметов, географии предлагает использовать красочный способ репрезентации среды обитания человека в картинах, печатных текстах. Особое значение для развития полиэтнической культуры имеют самопрезентации региональной среды для создания реальности через конструирование школьниками виртуальных объектов и маршрутов [12].

Средства многонациональной среды региона мы понимаем в двух позициях: а) носитель и источник учебной информации (организационные формы, объекты, созданные человеком, предметы региональной природы, культуры, техники), используемой в образовательном процессе; б) инструмент познания деятельности учителя и школьника для развития полиэтнической культуры.

В рамках настоящего исследования придерживаемся точки зрения П. И. Пидкасистого, раскрывающего идеальные и материальные средства развития культуры школьника [14]. Отметим тот факт, что развитие полиэтнической культуры становится эффективным, если выделенные материальные и идеальные средства среды региона взаимосвязаны и работают на одну цель.

К материальным средствам относим средства на печатной основе (тексты, таблицы, карты (имен- ные, информационные, когнитивные), содержательные модули) - носители и источники дополнительной полиэтнической информации, развивающие первоначальные представления о полиэтнических явлениях, фактах, понятиях.

Идеальные средства - информационные средства (презентации Power Point, веб-квесты, электронные поисковые системы, интерактивные технологии, творческие, исследовательские проекты, развивающие задания, программы - все это источники систематизации, коммуникации, выхода за границы заданной полиэтнической информации.

Нами накоплен такой опыт совместно с учителями Кондинского, Уватского, Сургутского районов. Дополнительно был проведен отбор средств на печатной основе, информационных технологий, система развивающих заданий. При этом уместно раскрыть позицию В. Л. Каганского, который отмечает, что регион - это прежде всего аналог текста, а работа с таким текстом - путешествие в мир контекстов [15]. Особым средством развития полиэтнической культуры является картографирование событий через изучение карт разного назначения: именных, хронологических и др. для расширения среды когнитивных представлений, как отмечает C. A. Grant [16].

Совокупность средств является оптимальной и достаточной на отработку приемов по обобщению полиэтнической информации (таблица).

Отметим эффективные формы активизации процесса развития полиэтнической культуры. Среди них предпочтительно следует выбирать коллективно-групповые занятия, а именно нестандартные уроки: урок-диалог, урок-дискуссия, урок-викторина, урок-конференция, урок-круглый стол.

Средние значения уровневого распределения школьников по компонентам развития полиэтнической культуры средствами многонационального региона на констатирующем этапе эксперимента составили: высокий уровень 6,3% (КГ), 5,9 \% (ЭГ); средний уровень 21,9 \% (КГ), 14,7 \% (ЭГ); низкий уровень 71,8 \% (КГ), 79,4 \% (ЭГ). Высокий уровень развития имеет примерно одинаковое число школьников, что отражается соотношением (1 : 0,89); на низком уровне развития находится большее число школьников экспериментальной группы; средний уровень развития полиэтнической культуры наиболее ярко выражен у школьников контрольной группы (КГ).

В ходе констатирующего этапа выделены следующие проблемы в развитии полиэтнической культуры: недостаточность мотивации школьников (32\%); отсутствие интереса и потребности в изучении полиэтнической информации (42 \%); низкий уровень знаний о многонациональной среде региона (14 \%), недостаточное проявление комму- 
никативных умений $(20,5$ \%), гражданской идентичности $(21,9 \%)$, уровень развития эмпатии (35\%), уровень развития этничности школьников $(15,6 \%)$, отсутствие умений анализировать и оценивать полиэтническую информацию, работать со средствами многонациональной среды региона (21,1 \%), что затрудняет полиэтническое взаимодействие школьников на основе диалога, командной работы.

\section{Заключение}

Научный концепт «региональная среда» в ее социокультурной, исторической, полиэтнической обусловленности преобразуется в условиях глобальных изменений, углубления культурных различий. Знание достижений многонациональной среды региона - необходимое условие развития полиэтнической культуры, обеспечивающей бесконфликтное взаимодействие школьников с представителями разных культур и важный фактор осознанного понимания конструкта «прошлое, настоящее, будущее» региона в единстве и во взаимосвязи; успеш- ная организация полиэтнической культуры и управление ее развитием возможны на основе приращения системы знаний, умений, качеств полиэтнического характера и опыта по их приобретению, с учетом усложнения видов деятельности по этапам: энкультурации - развитие этничности; инкультурации - развитие полиэтнической образованности; аккультурации - развитие полиэтничности как универсального качества при соблюдении комплекса педагогических условий:

- создание особой развивающей среды через включение в образовательный процесс современных проявлений многонациональной среды региона;

- использование в учебно-методическом обеспечении средств на основе многонациональной среды региона для каждого школьника на максимальном уровне;

- организация обучения с применением интерактивных методов, форм занятий, технологий ИКТ;

- развитие положительной мотивации школьников как системы потребностей, мотивов, интересов.

\section{Список литературы}

1. Бороноев А. О. Территория ментальности и проблемы социокультурного развития региона. СПб.: Астерион, 2006. С. 7.

2. Поздеева С. И. Рецензия на книгу Цзинь Ли «Культурные основы обучения: Восток и Запад» // Вестник Том. гос. пед. ун-та (TSPU Bulletin). 2019. Вып. 3 (200). С. 109-111.

3. Егорова Г. И., Сязи Н. М. Формирование полиэтнической культуры как основа социализации обучающихся в современных условиях // Современные проблемы науки и образования. 2015. № 5.

4. Арутюнян Ю. В. Этносоциология. М.: Аспект-Пресс, 1998. 271 с.

5. Демин А. М. Разработка и реализация национально-регионального компонента поликультурного образования в старших классах средней общеобразовательной школы: дис. ... канд. пед. наук. Барнаул, 2008. 212 с.

6. Буряк Н. Ю. Культура языковой личности в поликультурной среде вуза: дис. ... канд. культурологии. Краснодар, 2012. 291 с.

7. Лихачев Д. С. Ценности культуры // Русская культура: сб. М.: Искусство, 2016. С. 197-209.

8. Ахияров К. Ш. Теоретические основы школьного краеведения // Краевая научно-исследовательская лаборатория по проблемам личности в поликультурной среде / под ред. В. Н. Гурова. Ставрополь, 2003. 126 с.

9. Джуринский А. Н. Педагогика межнационального общения: поликультурное воспитание в России и за рубежом: учеб. пособие. М.: ТЦ Сфрера, 2007. 206 c.

10. Смирнова Ю. В. Воспитание межнациональной толерантности старшеклассников в общеобразовательной школе: дис. ... канд. пед. наук. СПб., 2012. 176 c.

11. Карпушина Л. П., Соколова П. Ю. Социализация детей и подростков в условиях этнокультурной образовательной среды. Саранск: Мордов. гос. пед. ин-т, 2011. $181 \mathrm{c.}$

12. Матрусов И. С. Краеведение и краеведческий подход в преподавании географии. М.: Изд-во АПН РСФСР, 2000. 151 С.

13. Егорова Г. И. Сущностные основы полиэтнической культуры современной образовательной системы // Известия высших учебных заведений. Социология. Экономика. Политика. 2013. № 2. С. 92-94.

14. Пидкасистый И. П. Психология и педагогика: учебник для бакалавров. М.: Юрайт, 2016. 724 с.

15. Каганский В. Л. Методологические основания регионального анализа как культурной практики // Культура в современном мире. 1997. Вып. 3. С. 4-29.

16. Grant C. A. Multicultural education: Commitments, issues, and applications. Washington, DC: Association for Supervision and Curriculum Development, 1977.

Егорова Галина Ивановна, профессор, доктор педагогических наук, Тюменский индустриальный университет (ул. Володарского, 38, Тюмень, Россия, 625100). E-mail: egorovagi@list.ru

Сязи Надежда Максимовна, учитель, Муниципальное бюджетное образовательное учреждение 2 (ул. Тарасова, 27, Тарко-Сале, Ямало-Ненецкий автономный округ, Россия, 629850). E-mail: nsyazi@mail.ru 
Чабарова Бибинур Мутовна, кандидат педагогических наук, доцент, Тюменский государственный университет (ул. Семакова 10, Тюмень, Россия, 625100). E-mail: bchabarova@mail.ru

Материал поступил в редакцию 18.11.2019.

DOI: $10.23951 / 1609-624 X-2020-1-24-32$

\title{
EDUCATIONAL POTENTIAL OF THE REGIONAL ENVIRONMENT IN THE SYSTEM OF DEVELOPMENT OF POLYETHNIC CULTURE OF SCHOOLCHILDREN
}

\author{
G. I. Egorova ${ }^{1}$, N. M. Syazi ${ }^{2}$, B. M. Chabarova ${ }^{3}$ \\ ${ }^{1}$ Tyumen Industrial University, Tyumen, Russian Federation \\ ${ }^{2}$ Municipal budgetary educational institution 2, Tarko-Sale, Russian Federation \\ ${ }^{3}$ Tyumen State University, Tyumen, Russian Federation
}

Introduction. The appeal of teachers, scientists to the scientific concept of "regional environment" is a timely need, due to global changes and the deepening cultural differences of each region. Knowledge of the achievements of the multinational environment of the region is considered as an important condition for the development of a multi-ethnic culture, ensuring conflict-free interaction between schoolchildren and representatives of different cultures and an important factor in a conscious understanding of the regional construct "past, present, future" of the region in unity and in interconnection.

The purpose of the article is to reveal the possibilities of teaching aids based on the multinational environment of the region in the development of a multi-ethnic culture of schoolchildren, to identify their functional and didactic significance, and conditions of use.

Materials and methods. The research material was developed on the basis of the multinational environment of the region: content modules, printed media (tables, maps, developmental tasks, technologies). The following methods were used: theoretical and methodological analysis of the leading concepts on the topic under study, content analysis, a selection of leading authors on the studied problem, comparative, benchmarking analysis). In the study of pedagogical experience, the method of classification, analogies, content analysis was used. Empirical methods included questioning, conversation, comparative analysis. Statistical methods were based on mathematical analysis methods.

Results. Content modules based on the multinational environment of the region that enhance the variability and invariant of subject knowledge have been developed and implemented: the cultural module reveals the multi-ethnic function of subject knowledge through studying the culture of ethnic groups, their role in the development of the region; the historical module creates a holistic view of the history of the region, multinational construction sites, heroes, discoverers of the Siberian land; ecological - geographical module takes into account the living conditions of ethnic groups with a rapid change of technology; socio-economic module shows the role of ethnic groups in the development of natural resources, industry of the region. The necessity of the phased development of a multi-ethnic culture of schoolchildren through the consistent inclusion of teaching aids based on the multinational environment of the region (texts, tables, maps (personal, cognitive, informational, web-quests); a system of developing tasks, interactive technologies that update knowledge and skills of a multi-ethnic nature is proved.

Conclusion. At the end of the article, the results of the study are summarized, the practical significance of the use of teaching aids based on the multinational environment of the region as the basis for the development of a multi-ethnic culture of students is revealed.

Keywords: region, regional space, regional environment, teaching aids, multi-ethnic culture.

\section{References}

1. Boronoyev A. O. Territoriya mental'nosti i problemy sotsiokul'turnogo razvitiya regiona [Territory of mentality and problems of socio-cultural development of the region].Saint Petersburg, Asterion Publ., 2006. P. 7 (in Russian).

2. Pozdeyeva S. I. Retsenziya na knigu Tszin' Li «Kul'turnye osnovy obucheniya: Vostok i Zapad» [Book review.Jin Li "Cultural Foundations of Learning: East and West"]. Vestnik Tomskogo gosudarstvennogo pedagogicheskogo universiteta - TSPU Bulletin, 2019, no. 3 (200), pp. 109-111 (in Russian).

3. Egorova G. I., Syazi N. M. Formirovaniye polietnicheskoy kul'tury kak osnova sotsializatsii obuchayushchikhsiya v sovremennykh usloviyakh [The formation of a multi-ethnic culture as the basis for the socialization of students in modern conditions]. Sovremennye problemy nauki $i$ obrazovaniya - Modern problems of science and education, 2015, no. 5 (in Russian).

4. Arutyunyan Yu. V. Etnosotsiologiya [Ethnosociology]. Moscow, Aspekt Press Publ., 1998. 271 p. (in Russian).

5. Demin A. M. Razrabotka i realizatsiya natsional'no-regional'nogo komponenta polikul'turnogo obrazovaniia v starshikh klassakh sredney obshcheobrazovatel'noy shkoly. Dis. kand. ped. nauk [Development and implementation of the national-regional component of multicultural education in the upper grades of the secondary school. Diss. cand. ped. sci.]. Barnaul, 2008. 212 p. (in Russian).

6. Buryak N. Yu. Kul'tura yazykovoy lichnosti v polikul'turnoy srede vuza. Dis. ... kand. kul'turologii [The culture of a linguistic personality in the multicultural environment of a university. Dis. cand. cultural sci.]. Krasnodar, 2012. 291 p. (in Russian).

7. Likhachev D. S. Tsennosti kul'tury [The values of culture]. Russkaya kul'tura: sbornik [Russian culture: collection]. Moscow, Iskusstvo Publ., 2016. pp. 197-209 (in Russian). 
8. Akhiyarov K. Sh. Teoreticheskiye osnovy shkol'nogo krayevedeniya [Theoretical Foundations of the School of Local Lore]. Krayevaya nauchnoissledovatel'skaya laboratoriya po problemam lichnosti v polikul'turnoy srede. Pod red. V. N. Gurova [Regional Research Laboratory for Personality Problems in a Multicultural Environment. Under the editorship of V. N. Gurova]. Stavropol', 2003. 126 p. (in Russian).

9. Dzhurinskiy A. N. Pedagogika mezhnatsional'nogo obshcheniya: polikul'turnoye vospitaniye v Rossii i za rubezhom: ucheb. posobiye [Pedagogy of interethnic communication: multicultural education in Russia and abroad: tutorial]. Moscow, TTs Sfera Publ., 2007. 206 p. (in Russian).

10. Smirnova Yu. V. Vospitaniye mezhnatsional'noy tolerantnosti starsheklassnikov v obshcheobrazovatel'noy shkole. Dis. kand. ped. nauk [Education of interethnic tolerance of senior pupils in a comprehensive school. Dis. ... cand. ped sci.]. Saint Petersburg, 2012. 176 p. (in Russian).

11. Karpushina L. P., Sokolova P. Yu. Sotsializatsiya detey i podrostkov v usloviyakh etnokul'turnoy obrazovatel'noy sredy [The socialization of children and adolescents in an ethnocultural educational environment]. Saransk, Mordov State Ped. in-t Publ., 2011. 181 p. (in Russian).

12. Matrusov I. S. Krayevedeniye $i$ kraevedcheskiy podkhod v prepodavanii geografii [Local history and local history approach in the teaching of geography]. Moscow, Academy of Pedagogical Sciences of the RSFSR Publ., 2000.151 p. (in Russian).

13. Egorova G. I. Sushchnostnye osnovy polietnicheskoy kul'tury sovremennoy obrazovatel'noy sistemy [The essential foundations of the multiethnic culture of the modern educational system]. Izvestiya vysshikh uchebnykh zavedeniy. Sotsiologiya. Ekonomika. Politika - Proceedings of Higher Educational Institutions. Sociology. Economics. Politics, 2013, no. 2, pp. $92-94$ (in Russian).

14. Pidkasistyy I. P. Psikhologiya i pedagogika: uchebnik dlya bakalavrov [Psychology and pedagogy: a textbook for bachelors]. Moscow, Yurayt Publ., 2016. 724 p. (in Russian).

15. Kaganskiy V. L. Metodologicheskiye osnovaniya regional'nogo analiza kak kul'turnoy praktiki [Methodological foundations of regional analysis as a cultural practice]. Kul'tura v sovremennom mire, 1997, no. 3, pp. 4-29 (in Russian).

16. Grant C. A. Multicultural education: Commitments, issues, and applications. Washington, DC: Association for Supervision and Curriculum Development, 1977.

Egorova G. I., Tyumen Industrial University (ul. Volodarskogo, 38, Tyumen, Russian Federation, 625100). E-mail: egorovagi@list.ru

Syazi N. M., Municipal budgetary educational institution 2 (ul. Tarasova, 27, Tarko-Sale, Yamalo-Nenets Autonomous Okrug, Russian Federation, 629850).E-mail: nsyazi@mail.ru

Chabarova B. M., Tyumen State University (ul. Semakova, 10, Tyumen, Russian Federation, 625100).

E-mail: bchabarova@mail.ru 